\title{
Synthesis, thermal, structural and electrical properties of vanadium-doped lithium-manganese-borate glass and nanocomposites
}

\author{
Agata Jarocka $^{1}$ - Przemysław P. Michalski ${ }^{1}$ - Jacek Ry| ${ }^{2}$ - Marek Wasiucionek ${ }^{1}$. Jerzy E. Garbarczyk ${ }^{1}$. \\ Tomasz K. Pietrzak ${ }^{1}$
}

Received: 25 March 2019 / Revised: 1 August 2019 / Accepted: 23 August 2019 / Published online: 11 November 2019

(C) The Author(s) 2019

\begin{abstract}
A glassy sample with a nominal formula $\mathrm{LiMn}_{1-3 x / 2} \mathrm{~V}_{x} \mathrm{BO}_{3}$ (where $x=0.05$ ) was synthesised using the melt-quenching method. Material was characterised by differential thermal analysis (DTA), X-ray diffactometry (XRD) at room temperature and as a function of temperature (HT-XRD), X-ray photoelectron spectroscopy (XPS), impedance spectroscopy (IS) and scanning electron microscopy (SEM). Dependences of glass transition and crystallisation temperatures on the heating rate in DTA experiments were determined. The initial value of electrical conductivity of the glass was $1.4 \times 10^{-15} \mathrm{Scm}^{-1}$. It was significantly increased by a proper thermal nanocrystallisation. The maximum value was higher by 6 orders of magnitude and reached $2.6 \times 10^{-9} \mathrm{Scm}^{-1}$ at room temperature. Expected crystalline phases (i.e. monoclinic and hexagonal $\mathrm{LiMnBO}_{3}$ ) upon heating were identified and assigned to thermal events observed with DTA. Microstructure of nanocrystalline samples observed by SEM revealed nanocrystalline grains noticeably smaller than $100 \mathrm{~nm}$. Results explaining nanocrystallisation process are coherent.
\end{abstract}

Keywords Lithium-manganese-borate glasses · Nanocrystallisation · Vanadium doping · Conductivity increase

\section{Introduction}

Nowadays, rapid technology development in the fields of portable electronic devices or electric cars requires novel, technologically mature, safe and economically affordable portable power sources. Especially, the demand for more efficient and lighter Li-ion cells is growing extremely quickly. One of the factors that has crucial influence on batteries' performance is the electrical conductivity of their cathode materials. Therefore, it is very important to carry out researches on better cathode materials as well as methods to improve their properties.

Recently, an interesting way to enhance electrical conductivity of such materials has been proposed [1, 2],

Tomasz K. Pietrzak

tomasz.pietrzak@pw.edu.pl

1 Faculty of Physics, Warsaw University of Technology, Koszykowa 75, PL-00-662, Warsaw, Poland

2 Faculty of Chemistry, Gdańsk University of Technology, Narutowicza 11/12, PL-80-233, Gdańsk, Poland namely thermal nanocrystallisation of glassy analogues of cathode materials for lithium- and sodium-ion batteries. This method was successfully applied to vitreous $\mathrm{V}_{2} \mathrm{O}_{5}$ $\mathrm{P}_{2} \mathrm{O}_{5}$ [3], $\mathrm{Li}_{2} \mathrm{O}-\mathrm{FeO}-\mathrm{V}_{2} \mathrm{O}_{5}-\mathrm{P}_{2} \mathrm{O}_{5}$ [4, 5], $\mathrm{LiF}-\mathrm{V}_{2} \mathrm{O}_{5}-\mathrm{P}_{2} \mathrm{O}_{5}$, $\mathrm{Li}_{2} \mathrm{O}-\mathrm{FeO}-\mathrm{B}_{2} \mathrm{O}_{3}$ [6] and some other systems, usually resulting in a giant increase in the electrical conductivity. In high-conducting nanomaterials, nanocrystallites with sizes between 5 and $100 \mathrm{~nm}$ were embedded in a residual glassy matrix. Highly disordered shells provided favourable conditions for electron hopping between aliovalent ions of transition metals, e.g. Fe, V, and Ti.

While many reports have been published on phosphate polyanion cathode materials [7], in recent years, there has been also interest in lithium-manganese-borate (nominally $\mathrm{LiMnBO}_{3}$ ) compound. It is due to its high theoretical gravimetric capacity $\left(222 \mathrm{mAhg}^{-1}[8-12]\right)$ that originates from low molar mass of the borate group. Moreover, $\mathrm{B}_{2} \mathrm{O}_{3}$ is a very well-known glass former. Therefore, it was natural to synthesise a glassy analogue of $\mathrm{LiMnBO}_{3}$ and try to improve its modest electrical conductivity by thermal nanocrystallisation [13]. Despite many efforts and comprehensive studies, the final values of electrical 
conductivity have been unsatisfactory. Therefore, we decided to introduce some vanadium dopant to the system, which should have positive influence on the electronic conduction. Its good effect on electrical properties of materials was proven by previous studies on vanadiumdoped $\mathrm{LiFePO}_{4}$ in polycrystalline phase (e.g. $\left.[14,15]\right)$ and in nanostructural glass-ceramics (e.g. [4]).

\section{Experimental}

Synthesis. The aim was to synthesise a glassy sample with a nominal formula $\mathrm{LiMn}_{1-3 x / 2} \mathrm{~V}_{x} \mathrm{BO}_{3}$ where $x=$ 0.05 to have vanadium presumably at $3+$ oxidation state. Investigated sample was obtained using the melt-quenching method. Stoichiometric amounts of $\mathrm{Li}_{2} \mathrm{CO}_{3}$ (POCH, Polish Chemicals, p.a., 1.1194 g), $\mathrm{V}_{2} \mathrm{O}_{5}$ (Aldrich, p., $0.1378 \mathrm{~g}$ ), $\mathrm{Mn}\left(\mathrm{CH}_{3} \mathrm{COO}\right)_{2} \times 4 \mathrm{H}_{2} \mathrm{O}$ (Aldrich, p., $6.8688 \mathrm{~g}$ ) and $\mathrm{H}_{3} \mathrm{BO}_{3}$ $(\mathrm{POCH}$, p.a., $1.8740 \mathrm{~g}$ ) were used. Substrates were ground in a planetary mill (Retsch PM100). The pulverised powder was placed in a porcelain crucible and then put into a furnace preheated to $1125^{\circ} \mathrm{C}$ and kept there for $15 \mathrm{~min}$. An outer bigger crucible filled with graphite (so called double crucible technique [16]) was used to prevent $\mathrm{Mn}^{2+}$ from oxidation and to reduce vanadium to $3+$ oxidation state. Melted batch was rapidly quenched between two stainless steel plates in order to obtain glassy material [5].

Characterisation methods Samples of as-received material were characterised by the following methods: differential thermal analysis (DTA), X-ray diffractometry (XRD) at room temperature and as a function of temperature (HTXRD), high-resolution X-ray photoelectron spectroscopy (XPS), impedance spectroscopy (IS) and scanning electron microscopy (SEM).

Differential thermal analysis was used to investigate thermal events occurring in the sample while heating with different rates and to determine its characteristic temperatures of glass transition $\left(T_{g}\right)$, crystallisation $\left(T_{c}\right)$ and melting $\left(T_{m}\right)$. Measurements were carried out with a Q600 analyser (TA Instruments) and the results were analysed with the TA Universal Analysis software. Samples were measured in argon flow at temperature ranging from room temperature to $800{ }^{\circ} \mathrm{C}$ and with the heating rates from 1 to $40{ }^{\circ} \mathrm{Cmin}^{-1}$ in order to observe process kinetics.

Powder X-ray diffractometry studies were performed with Philips X'Pert Pro diffractometer equipped with a copper lamp $\left(\mathrm{CuK}_{\alpha}=1.54 \AA\right)$. Measurements were firstly carried out at room temperature to verify amorphousness of the material and consequently at elevated temperatures up to $650{ }^{\circ} \mathrm{C}$ with $1{ }^{\circ} \mathrm{Cmin}^{-1}$ heating rate to observe crystallisation processes. The temperature of the sample was stabilised for 15 min before acquisition of each pattern, which lasted for another $22 \mathrm{~min}$. In this experiment, an Anton Paar HTK-1200 furnace and nitrogen flow were used. One additional measurement was done for the sample previously annealed at $700{ }^{\circ} \mathrm{C}$ in a separate chamber furnace. It was necessary to perform additional annealing ex situ, because the proximity of the sample's melting point prevented from performing whole measurement in situ (it posed a risk of accidental liquefying of the sample during an ongoing XRD measurement which could damage at least the sample holder of the diffractometer).

In order to determine the relative concentration of $\mathrm{Mn}^{2+} / \mathrm{Mn}^{3+}$, high-resolution X-ray photoelectron spectroscopy (XPS) studies were carried out on an Escalab $250 \mathrm{Xi}$ from Thermofisher Scientific at Gdańsk University of Technology. The spectroscope was equipped with $\mathrm{Al} K_{\alpha}$ source, pass energy was $30 \mathrm{eV}$ and the spot size diameter 250 micrometre. Charge compensation was controlled through the low-energy electron and low-energy $\mathrm{Ar}^{+}$ ion emission by means of a flood gun (emission current $150 \mathrm{~mA}$, beam voltage $2.1 \mathrm{~V}$, filament current $3.5 \mathrm{~A}$ ), with normalisation of the $X$-axis (binding energy) for the peak characteristics of neutral carbon C 1 s $(284.6 \mathrm{eV})$ $[17,18]$. For deconvolution purposes Avantage software (Thermofisher Scientific) was used.

Microstructure of the samples were observed using scanning electron microscope Zeiss ULTRA Plus at the Institute of High Pressure Physics of the Polish Academy of Sciences. Previously annealed samples were cut just before the imaging in order to observe their cross-section. Material was covered with a thin layer of conductive carbon, because the conductivity of the samples was still unsatisfactory for high-resolution SEM observations.

Impedance spectroscopy was used to investigate electrical properties of the material. Studies were performed with a Novocontrol Alpha-A analyser in the frequency range from $10^{-2}$ to $10^{7} \mathrm{~Hz}$. To study the temperature dependence of the conductivity, the holder with the sample was placed in the oven (manufacturer: Czylok) equipped with temperature control system. Before measurement, platinum electrodes were sputtered on the both sides of the samples in a Baltec SCD500 sputter. A Eurotherm 2404 controller was used to provide temperature stabilisation as good as $0.1{ }^{\circ} \mathrm{C}$ during acquisition of the impedance spectrum at each temperature step. The whole measurement was fully automatised and controlled with a software developed in our group [19]. The heating/cooling rates between each impedance measurement were set to $5{ }^{\circ} \mathrm{Cmin}^{-1}$. Before acquisition of each spectrum, the sample was stabilised at fixed temperature for at least $30 \mathrm{~min}$. Therefore the effective heating/cooling rate was lower than $1{ }^{\circ} \mathrm{Cmin}^{-1}$. 


\section{Results and discussion}

\section{Differential thermal analysis}

The DTA trace acquired at the heating rate of $1{ }^{\circ} \mathrm{Cmin}^{-1}$ is presented in Fig. 1a. The curve was typical for a glassy material: a glass transition followed by two crystallisation peaks and one melting process were marked with arrows. The exact values of the temperature of these thermal events are given in Table 1. The presence of two exothermic peaks indicates multiphase character of the material after annealing. The glass transition temperature is quite similar to the value obtained for $\mathrm{LiMnBO}_{3}$ glass $\left(T_{g}=411^{\circ} \mathrm{C}\right)$, whereas the main crystallisation appeared at the temperature $\sim 60{ }^{\circ} \mathrm{C}$ higher [13]. This is in agreement with our previous studies on $\mathrm{LiFe}_{1-5 x / 2} \mathrm{~V}_{x} \mathrm{PO}_{4}$ nanomaterials, where $T_{c}$ increased with an increasing content of vanadium dopant [4].

In Fig. 1b, results for heating rates from $2{ }^{\circ} \mathrm{Cmin}^{-1}$ to $40{ }^{\circ} \mathrm{Cmin}^{-1}$ are shown. A step visible at the beginning for lower heating rates is not related to any thermal transition and was identified as an apparatus artefact. One can observe that transition temperatures strongly depend on heating rate: they are higher for faster heating rates. This behaviour is typical for DTA experiments and has been observed for many other glass systems (e.g. [20]).

$T_{g}$ and $T_{c}$ temperatures were determined for each heating rate to study process kinetics, according to Kissinger theory [21]. This theory describes dependency between the thermal
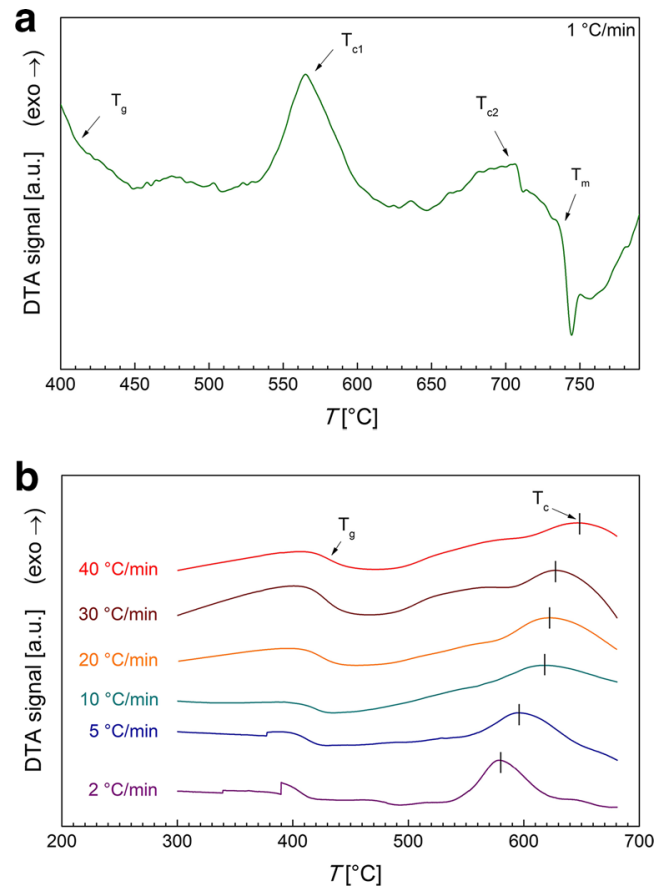

Fig. 1 DTA curves acquired at different heating rates: a $1{ }^{\circ} \mathrm{Cmin}^{-1}$ and $\mathbf{b}$ from 2 to $40^{\circ} \mathrm{Cmin}^{-1}$
Table 1 Glass transition, crystallisation and melting temperatures determined for the heating rate of $1{ }^{\circ} \mathrm{Cmin}^{-1}$

\begin{tabular}{llll}
\hline$T_{g}\left({ }^{\circ} \mathrm{C}\right)$ & $T_{c 1}\left({ }^{\circ} \mathrm{C}\right)$ & $T_{c 2}\left({ }^{\circ} \mathrm{C}\right)$ & $T_{m}\left({ }^{\circ} \mathrm{C}\right)$ \\
\hline 406 & 564 & 708 & 739 \\
\hline
\end{tabular}

event temperature and the heating rate. Its main equation can be written as

$\ln \left(\frac{\theta}{T_{m}^{2}}\right)=-\frac{E_{a}}{k_{B} T_{m}}+$ const

where $\theta$ is the heating rate, $T_{m}$ is the characteristic temperature for certain process, $E_{a}$ is the activation energy of the process, and $k_{B}$ is the Boltzmann constant.

In Fig. 2a, cumulative plots of the dependence of temperature of glass transition and crystallisation on the heating rates are shown in $\ln \left(\theta T^{-2}\right)$ vs. reciprocal of temperature coordinates. Activation energies were calculated as $E_{a}=2.90(21) \mathrm{eV}$ and $E_{a}=5.40(41) \mathrm{eV}$, accordingly. The value for the glass transition is around $1 \mathrm{eV}$ higher than the one obtained at our group for phosphate glasses containing vanadium (V) oxide and about $1 \mathrm{eV}$
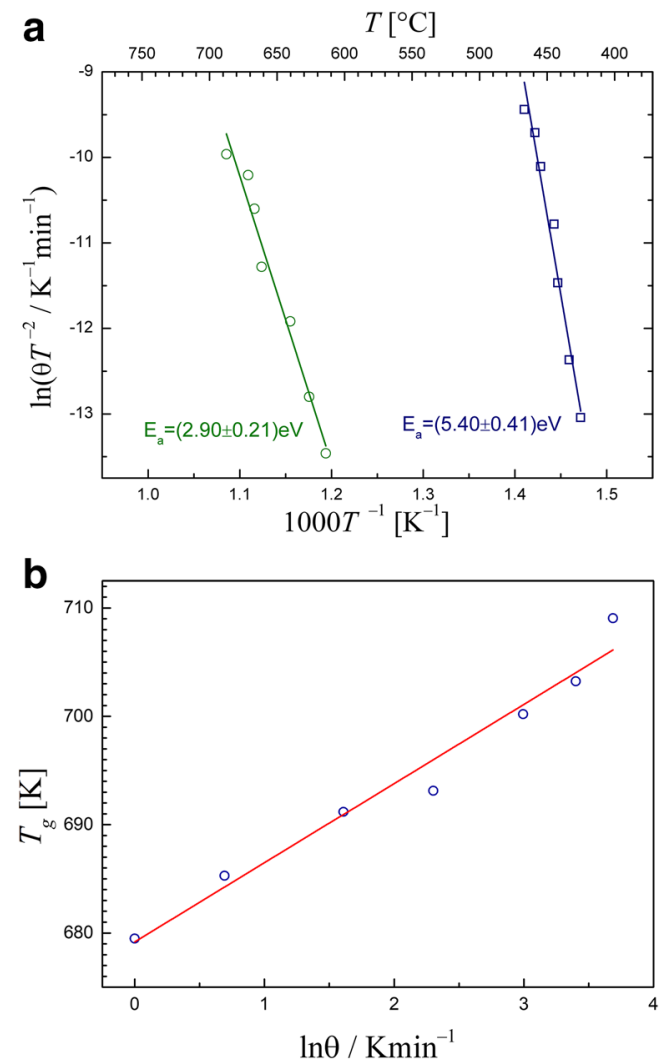

Fig. 2 a Kissinger plot for the investigated sample. Crystallisation temperatures are marked with green circles and glass transition ones with blue squares. Activation energies are given next to the data. b Lasocka plot for the investigated sample 


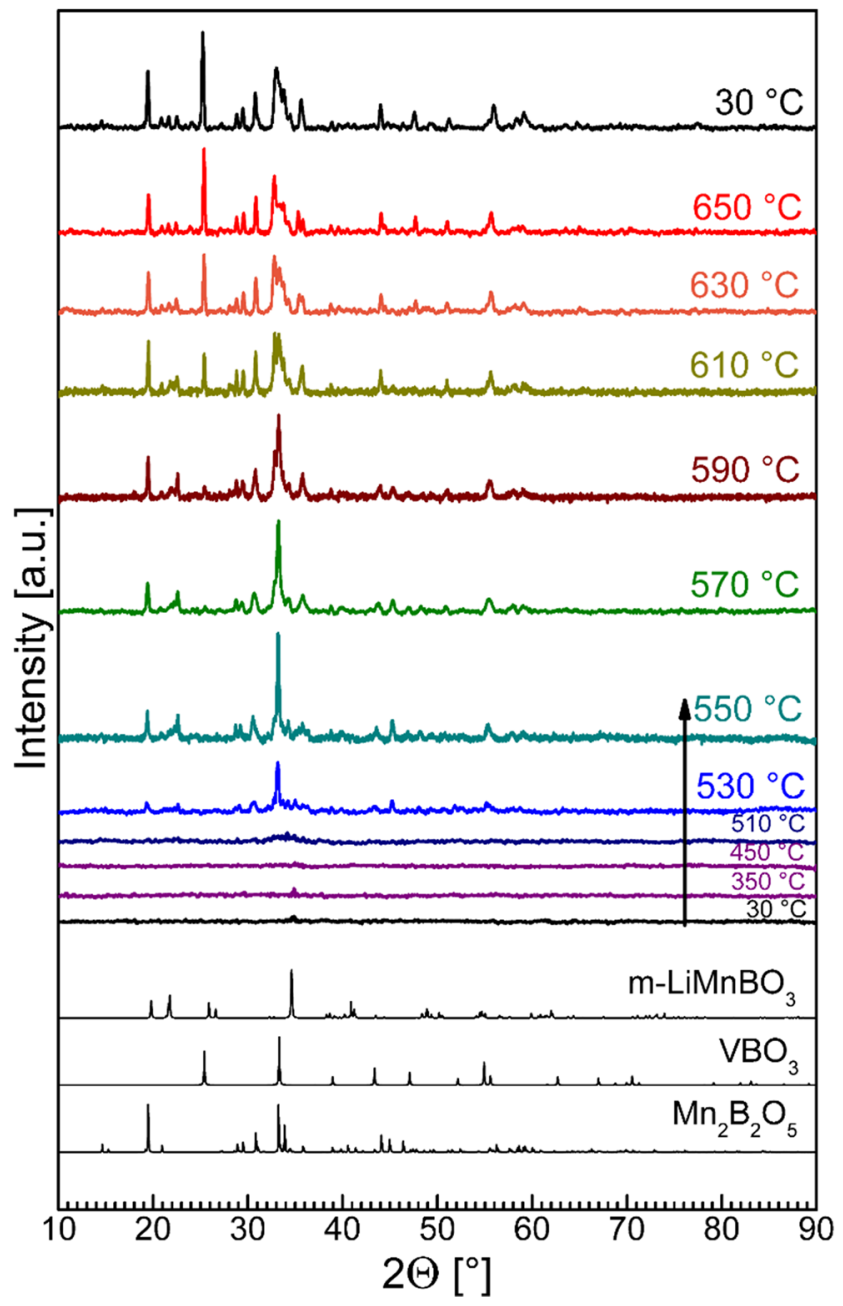

Fig. 3 Diffractograms for sample measured in the temperatures range $30-650{ }^{\circ} \mathrm{C}$ with $1{ }^{\circ} \mathrm{Cmin}^{-1}$ heating rate. XRD patterns for $\mathrm{m}$ $\mathrm{LiMnBO}_{3}, \mathrm{VBO}_{3}$ and $\mathrm{Mn}_{2} \mathrm{~B}_{2} \mathrm{O}_{5}$ phases are placed at the bottom

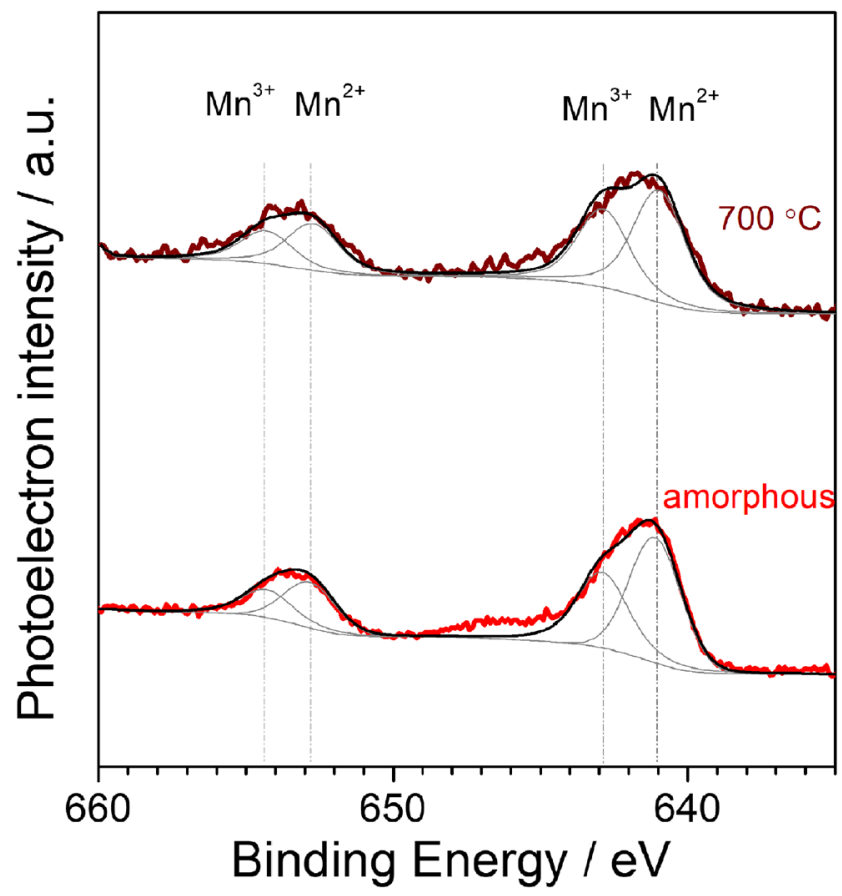

Fig. 5 High-resolution XPS spectra glassy sample and the sample crystallised at $700{ }^{\circ} \mathrm{C}$. Fitted profiles ascribed to presence of $\mathrm{Mn}^{2+}$ and $\mathrm{Mn}^{3+}$ ions are shown as grey lines above the background

lower than the one containing also lithium oxide and iron (II) oxide [20].

While Kissinger theory is the most frequently used in the field of crystallisation kinetics, there is another simpler approach proposed by Lasocka, which gives much a easier equation describing glass transition temperature vs. the heating rate [22]:

$T_{g}=A+B \ln \theta$
Fig. 4 Room temperature diffractograms of samples crystallised at $650{ }^{\circ} \mathrm{C}$ and $700^{\circ} \mathrm{C}$. Reference patterns of m-LiMnBO 3 , h-LiMnBO 3 , $\mathrm{VBO}_{3}$ and $\mathrm{Mn}_{2} \mathrm{~B}_{2} \mathrm{O}_{5}$ phases are shown below

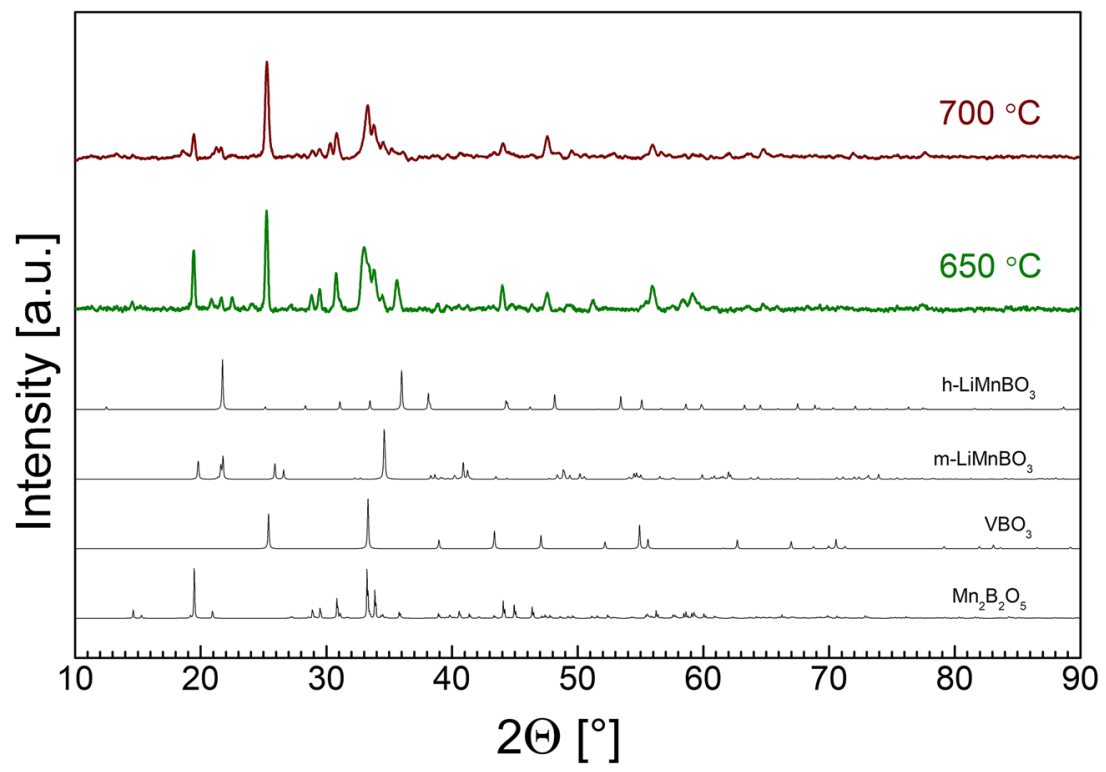


Table 2 The share of manganese oxidation states, based on highresolution XPS analysis

\begin{tabular}{lll}
\hline Label & $\mathrm{Mn}^{2+}$ & $\mathrm{Mn}^{3+}$ \\
\hline Amorphous & $58.3 \%$ & $41.7 \%$ \\
$700^{\circ} \mathrm{C}$ & $58.9 \%$ & $41.1 \%$ \\
\hline
\end{tabular}

where $T_{g}$ is the glass transition temperature, $A$ is the glass transition temperature when $\theta \rightarrow 1{ }^{\circ} \mathrm{Cmin}^{-1}, B$ is the constant, and $\theta$ is the heating rate.

In Fig. 2b (glass transition temperature in function of $\ln (\theta)$ ), one can see a linear fit of parameters $A$ and $B$ of Lasocka's equation. Hence, $B$ parameter was determined as 7.31(57) and $A$ parameter as 679.2(14) $\mathrm{K}$ $=406.0(14){ }^{\circ} \mathrm{C}$. It should be stressed that $A$ factor is equal to the glass transition temperature obtained from the direct DTA measurement $\left(T_{g}=406{ }^{\circ} \mathrm{C}\right)$ for heating rate $1{ }^{\circ} \mathrm{Cmin}^{-1}$. This value is probably very close to a glass transition temperature occurring at $\theta \rightarrow 0$.

\section{X-ray diffractometry}

X-ray diffractometry for the sample at room temperature confirmed amorphousness of the material, because of the absence of peaks characteristic for crystalline phases Fig. 3, black curve obtained for $30^{\circ} \mathrm{C}$.

First detectable peaks appeared at $530{ }^{\circ} \mathrm{C}$ and can be identified as $\mathrm{Mn}_{2} \mathrm{~B}_{2} \mathrm{O}_{5}$ (ICDD card no. 04-018-4266) phase. At $550{ }^{\circ} \mathrm{C}$ and $570{ }^{\circ} \mathrm{C}$, one can observe appearance of first traces of m-LiMnBO 3 (ICDD card no. 01-083-8511) and $\mathrm{VBO}_{3}$ (ICDD card no. 00-017-0311) peaks. Some small unidentified peaks originate from impurities from porcelain crucible $\left(\mathrm{LiAlSiO}_{4}\right)$. However, their amount is not significantly high.

Figure 4 presents $\mathrm{X}$-ray patterns (acquired at room temperature) of two samples: one heated up to $650{ }^{\circ} \mathrm{C}$ and the other one up to $700{ }^{\circ} \mathrm{C}$ with $1{ }^{\circ} \mathrm{Cmin}^{-1}$ heating rate, so that one can observe similarities and differences between them. It is clearly visible that most of the peaks of crystalline phases for both samples coincide, but still there are some differences-appearance of additional small peaks can be
Fig. 6 SEM micrographs of samples: a glass, b sample annealed at $600^{\circ} \mathrm{C}$, c sample annealed at $625^{\circ} \mathrm{C}$, d sample annealed at $675^{\circ} \mathrm{C}$, e sample annealed at $675^{\circ} \mathrm{C}$
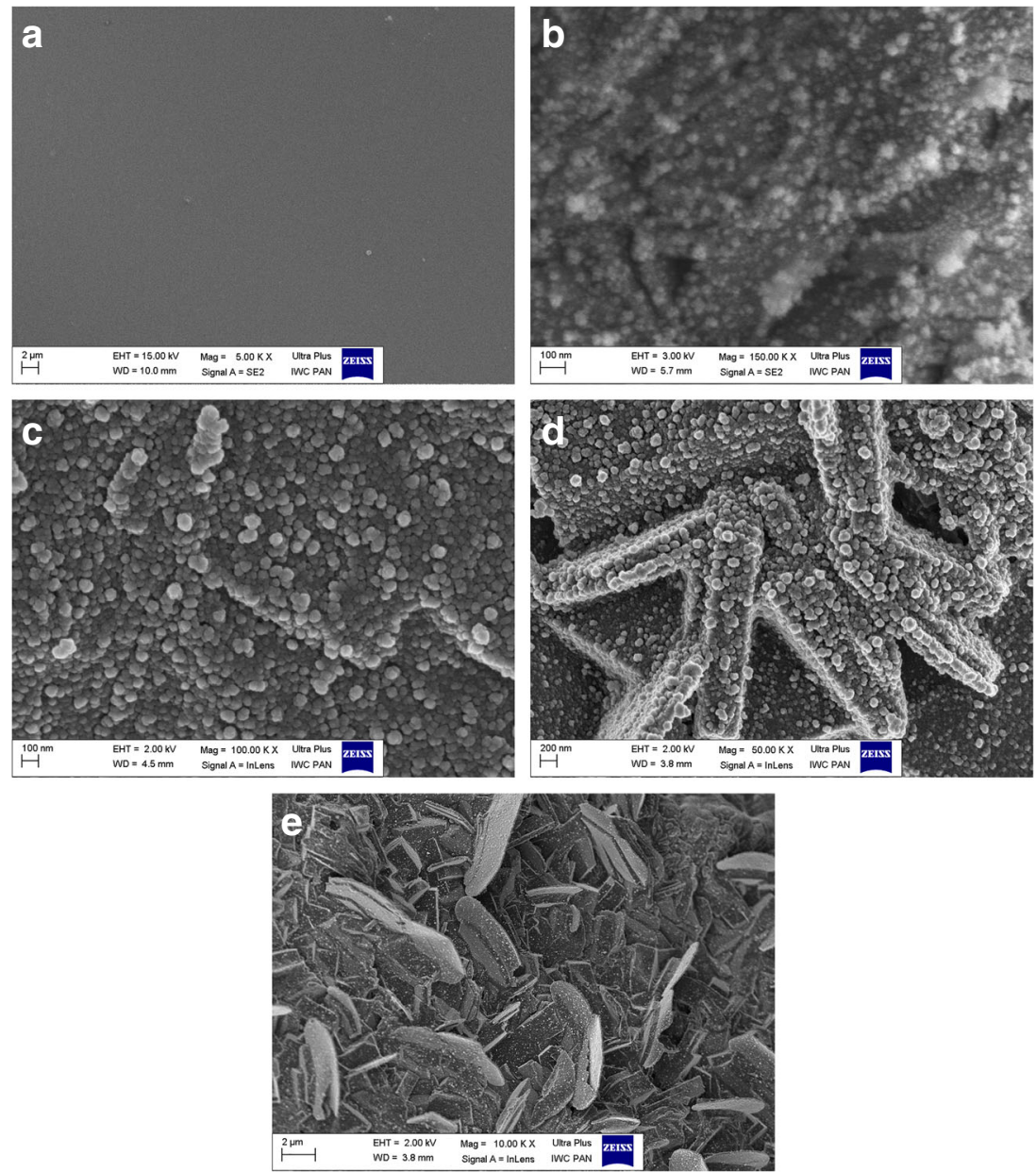
correlated with growth of h-LiMnBO 3 (ICDD card no. 00053-0371) phase at higher temperature. Therefore, phases that occurred at lower temperatures could be correlated with the first crystallisation temperature from DTA measurement $\left(T_{c 1}=564{ }^{\circ} \mathrm{C}\right)$ and $\mathrm{h}-\mathrm{LMB}$ phase with the second crystallisation $\left(T_{c 2}=708^{\circ} \mathrm{C}\right)$.

For reflexes ascribed to m-LiMnBO 3 and h-LiMnBO 3 phases, Scherrer estimation was used to determine crystallites sizes after nanocrystallisation at $700{ }^{\circ} \mathrm{C}$. Their values were as follows: for $\mathrm{m}$ - $\mathrm{LiMnBO}_{3}$-from 69 to exceeding $120 \mathrm{~nm}$ and for h-LiMnBO 3 -from 23 to $83 \mathrm{~nm}$. It should be emphasised that this method gives larger errors for grain sizes above $100 \mathrm{~nm}$, so the upper limit for m-LiMnBO 3 is not reliable. These calculations also confirm correlation with two crystallisations in the material. The grains of the monoclinic phase that appeared at the first crystallisation process have grown up and the crystallites of the hexagonal phase have just started to grow.

\section{High-resolution X-ray photoelectron spectroscopy}

In Fig. 5, a part of a high-resolution XPS spectrum for two samples-amorphous and nanocrystallised at $700{ }^{\circ} \mathrm{C}-$ used to determine relative shares of $\mathrm{Mn}^{2+}$ and $\mathrm{Mn}^{3+}$ ions is shown. Each sample was cut right before measurement in order to investigate the sample's cross-section that possibly had the shortest contact with air. The fitting procedure was carried out using Gaussian-Lorentzian functions. The exact shares of aliovalent manganese ions are shown in Table 2. One can see that relative ratio of $\mathrm{Mn}^{2+} / \mathrm{Mn}^{3+}$ concentration did not change significantly upon heating. Nevertheless, the experimental share of $\mathrm{Mn}^{2+}: \mathrm{Mn}^{3+}$ (approx. 3:2) differs noticeable from nominal composition, where only $\mathrm{Mn}^{2+}$ should be present. On the other hand, presence of aliovalent ions of transition metal oxide is desirable from the point of view of electron hopping, according to Mott's theory.

Similar analysis was performed for vanadium ions. It was, however, difficult due to low content of this element in the nominal formula. While no quantitate conclusions were drawn, the presence of $\mathrm{V}^{5+}$ line was observed. This means that the synthesis conditions (e.g. temperature or time) were not sufficient to lead to complete reduction of vanadium $\mathrm{V}^{5+}$ to $\mathrm{V}^{3+}$ and to prevent manganese from oxidation to $\mathrm{Mn}^{3+}$.

\section{Scanning electron microscopy}

Material's surface structure was investigated using scanning electron microscopy. In Fig. 6, selected SEM micrographs are presented.
Fig. 7 Nyquist plots obtained for investigated sample, a during heating at $170{ }^{\circ} \mathrm{C}$ and $\mathbf{b}$ during cooling (from $675^{\circ} \mathrm{C}$ ) at $170{ }^{\circ} \mathrm{C}$
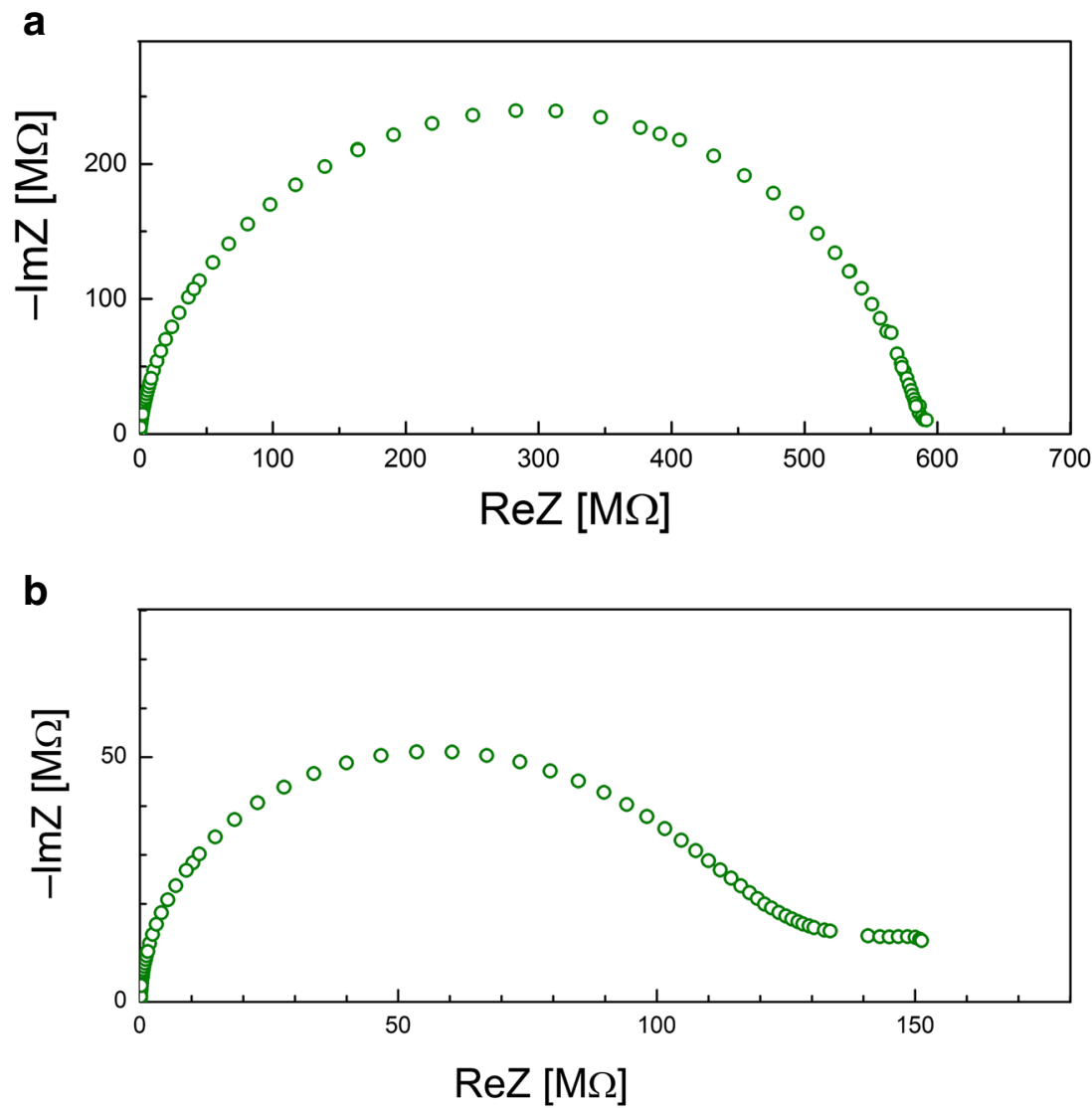


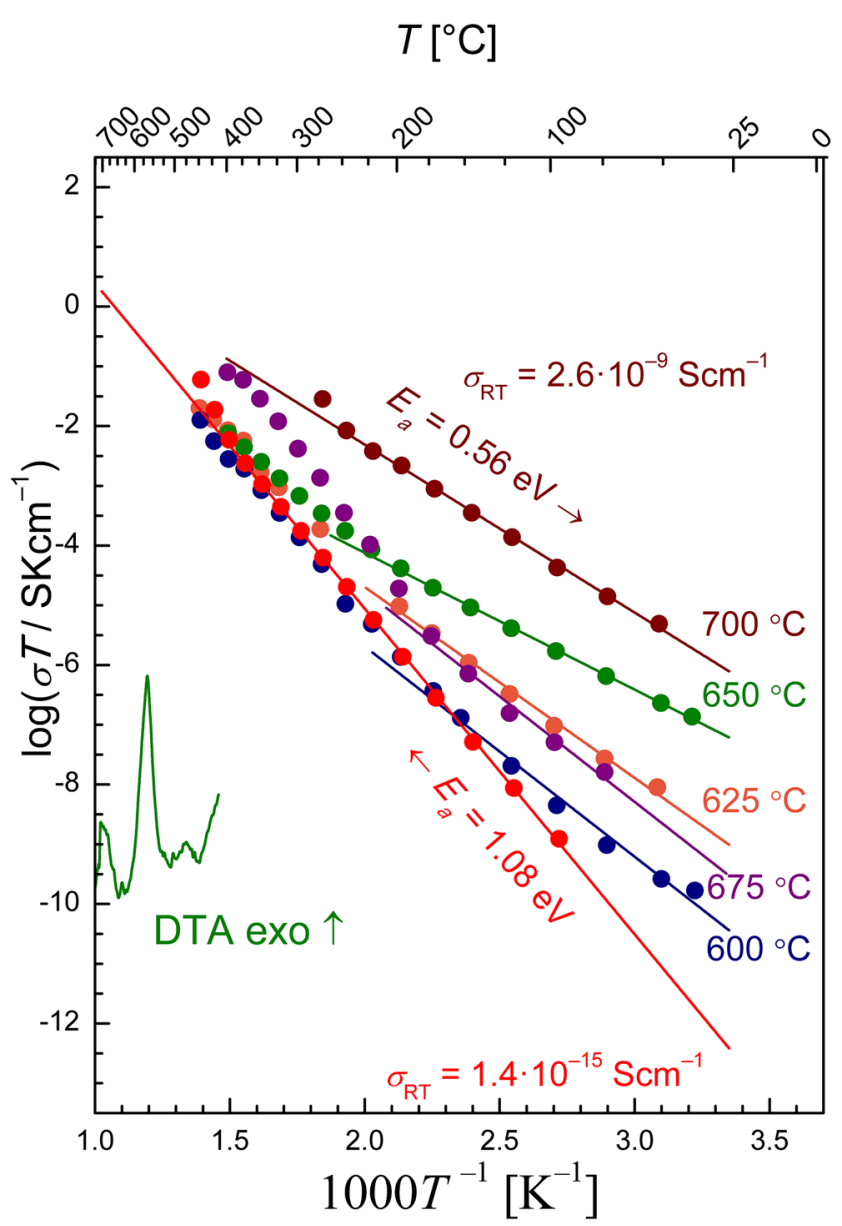

Fig. 8 The Arrhenius plot for different temperatures of annealing. Red circles represent heating and other colours of circles represent cooling from temperatures within the range $600-700{ }^{\circ} \mathrm{C}$. DTA curve is shown for comparison

Uniform surface and absence of visible grains (Fig. 6a) proves that initial sample was indeed vitreous and homogeneous. For the rest of the nanocrystalline samples, one can see one common feature - appearance of visible smaller bubble-shaped grains situated on bigger rod- or plate-shaped crystallites. Size of the smaller grains varies from a few to $100 \mathrm{~nm}$ while the bigger significantly exceed $100 \mathrm{~nm}$.

This phenomenon is in line with DTA (two crystallisations) and XRD (m-LiMnBO $3, \mathrm{VBO}_{3}$ and $\mathrm{Mn}_{2} \mathrm{~B}_{2} \mathrm{O}_{5}$ occurring at lower temperatures and $\mathrm{h}-\mathrm{LiMnBO}_{3}$ phase at higher ones as well as Scherrer estimations for their grain sizes) measurements. Furthermore, also better electrical properties of the nanocrystallised samples can be explained by appearance of smaller grains, most possibly h-LMB. All these observations are in line with other researchers' published works on similar topics $[11,25]$.

\section{Impedance spectroscopy}

In order to find optimal conditions for nanocrystallisation (i.e. to maximise the final conductivity), a few pieces of the amorphous sample were subjected to impedance spectroscopy measurements in a function of temperature. The experiments were carried out to different maximum temperatures for each piece $\left(600-700{ }^{\circ} \mathrm{C}\right)$, which were close to the second crystallisation temperature determined from the DTA curve. In Fig. 7a and b, one can see Nyquist plots at $\sim 170{ }^{\circ} \mathrm{C}$ during heating (glassy sample) and cooling (nanocrystalline sample) ramps. In the former case, one can observe a plain semicircle indicating predominant electronic character of the conductivity. At higher temperatures, a 'spur' was visible at low frequencies, which is characteristic for ionic conduction in the material (blocking $\mathrm{Li}^{+}$ ions at the Pt electrode). For a nanomaterial, one can distinguish two semicircles in the corresponding Nyquist plot (Fig. 7b).

The electrical conductivity was calculated from the impedance spectra. In Fig. 8, temperature dependence of the electrical conductivity diagrams for all of the results from impedance spectroscopy are presented in Arrhenius coordinates $\left(\log (\sigma T)\right.$ vs. $\left.1000 T^{-1}\right)$. Initial electrical conductivity for glassy samples at room temperature was too low to be measured directly. Hence, the linear fitting (in the Arrhenius coordinates) to data acquired at higher temperatures was extrapolated to room temperature. The exact values are given in Table 3. It is worth to mention that initial glass conductivity for every sample was almost identical what indicates homogeneity of obtained material. The average value was calculated as $1.4(3) \times 10^{-15} \mathrm{Scm}^{-1}$.

All of the values calculated from the measurements are presented in Table 3. The highest conductivity value was obtained for the nanocrystallisation at $700{ }^{\circ} \mathrm{C}$ and reached $2.6 \times 10^{-9} \mathrm{Scm}^{-1}$ (at RT) what gives increase in the

Table 3 Parameters obtained from impedance spectroscopy measurements

\begin{tabular}{|c|c|c|c|c|c|c|}
\hline Nanocrystallisation temperature $\left({ }^{\circ} \mathrm{C}\right)$ & $\sigma_{\mathrm{RT} \text { (glass) }}\left(\mathrm{Scm}^{-1}\right)$ & $\sigma_{\mathrm{RT}(\text { nano })}\left(\mathrm{Scm}^{-1}\right)$ & $\frac{\sigma_{\mathrm{RT}(\text { nano) }}}{\sigma_{\mathrm{RT}(\text { glass })}}$ & $E_{a \text { (glass) }}(\mathrm{eV})$ & $E_{a(\text { nano })}(\mathrm{eV})$ & $\frac{E_{a(\text { glass })}}{E_{a(\text { nano })}}$ \\
\hline 600 & $1.6 \times 10^{-15}$ & $1.2 \times 10^{-13}$ & 75.0 & 1.1 & 0.7 & 1.6 \\
\hline 625 & $9.4 \times 10^{-16}$ & $3.3 \times 10^{-12}$ & $3.5 \times 10^{3}$ & 1.1 & 0.6 & 1.8 \\
\hline 650 & $1.8 \times 10^{-15}$ & $2.1 \times 10^{-10}$ & $1.2 \times 10^{5}$ & 1.1 & 0.5 & 2.2 \\
\hline 675 & $1.7 \times 10^{-15}$ & $1.1 \times 10^{-12}$ & $6.5 \times 10^{2}$ & 1.1 & 0.7 & 1.6 \\
\hline 700 & $1.3 \times 10^{-15}$ & $2.6 \times 10^{-9}$ & $2.0 \times 10^{6}$ & 1.1 & 0.6 & 1.8 \\
\hline
\end{tabular}


Fig. 9 Arrhenius plot for sample nanocrystallised at $700{ }^{\circ} \mathrm{C}$ (full circles). Red circles represent heating and blue ones represent cooling. Corresponding DTA curve is shown for comparison. Empty circles correspond to results obtained for $\mathrm{LiMnBO}_{3}$ without vanadium doping [13]

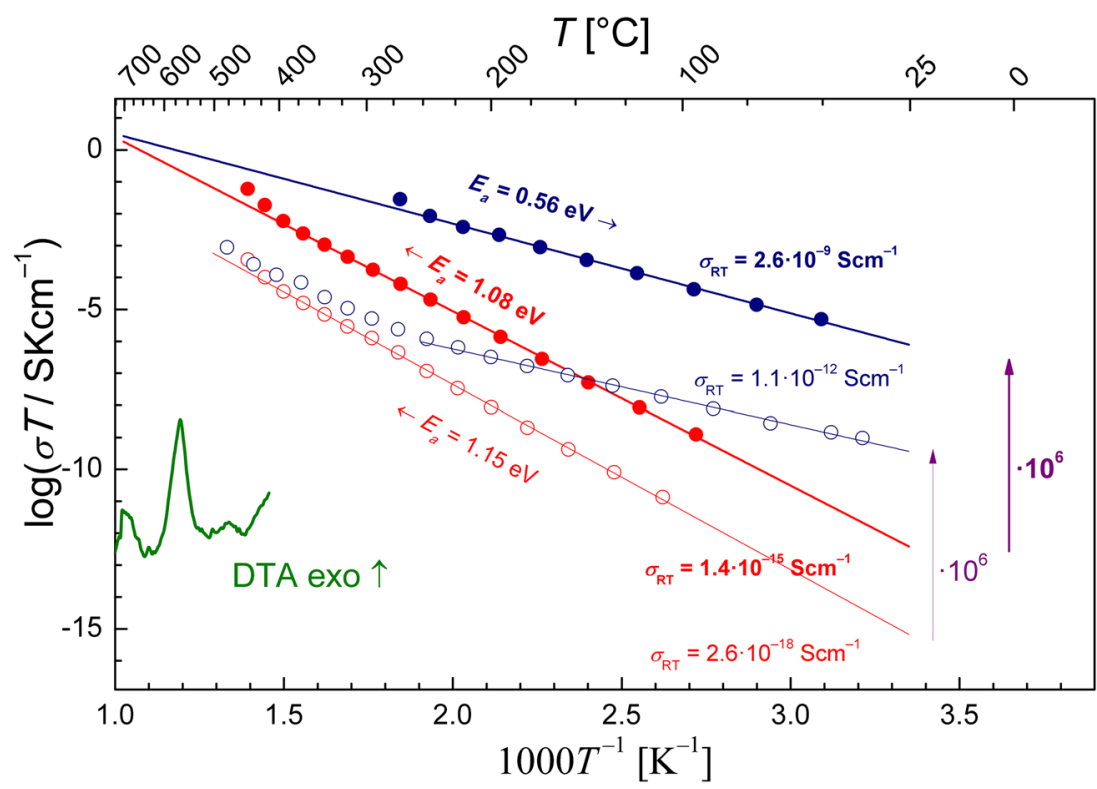

conductivity by $2 \times 10^{6}$. This measurement is also presented separately in Fig. 9 and compared with values for undoped $\mathrm{LiMnBO}_{3}$ [13]. One can see that the addition of vanadium caused boost in the conductivity value by 3 orders of magnitude. It is worth to mention that the difference was visible already in amorphous sample and has risen together with forming the nanocomposite. Furthermore, with thermal nanocrystallisation, the decrease in the activation energy value was also obtained. The lowest value of $E_{a}=0.5 \mathrm{eV}$ was observed for the sample heated to $650{ }^{\circ} \mathrm{C}$. However, values for all other measurements are similar: all of them are between 0.6 and $0.7 \mathrm{eV}$. The phenomenon of a significant increase in the conductivity and a decrease in the activation

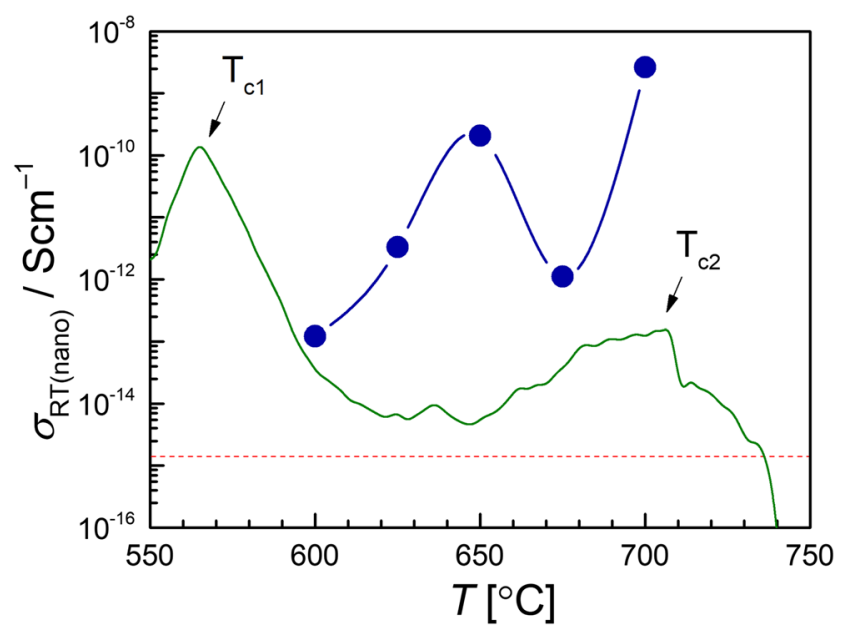

Fig. 10 Dependence of conductivity after nanocrystallisation vs. the annealing temperature. DTA curve is given for comparison-green solid line. Conductivity value for initial glassy sample was marked with red dashed line energy as a result of thermal nanocrystallisation was broadly discussed by us (e.g. in [1]) on a base of the Mott's theory of electron hopping in oxide glasses containing transition metal oxides [23].

In Fig. 10, one can see correlation between conductivity values for different annealing temperatures and crystallisation temperatures. Since both, DTA and IS, measurements were carried out with a comparable $\left(1{ }^{\circ} \mathrm{Cmin}^{-1}\right)$ heating rate, it is possible to combine the results. One can deduct that the highest obtained value is strictly associated with second crystallisation. The minimum appearing above $650^{\circ} \mathrm{C}$ may be attributed to a further growth of nanocrystallites, depressing the aforementioned effect of size in small nanocrystallites. Similar effect was observed previously in $\mathrm{V}_{2} \mathrm{O}_{5}-\mathrm{P}_{2} \mathrm{O}_{5}$ glasses [24].

\section{Conclusions}

In this work, a glassy vanadium-doped lithium-manganeseborate material was successfully synthesised with meltquenching method. Vitreous character of the sample was confirmed by DTA, XRD and SEM measurements. Glass transition temperatures measured at different heating rates followed both Lasocka's and Kissinger's formulas. Crystallisation temperatures also followed Kissinger's theory. Expected crystal phases were detected by XRD method in material after its appropriate annealing and identified. The highest conductivity at room temperature $(2.6 \times$ $10^{-9} \mathrm{Scm}^{-1}$ ) was obtained for the sample nanocrystallised at $700{ }^{\circ} \mathrm{C}$. This means a conductivity increase by a factor of $2 \times 10^{6}$. This value was also higher by 3 orders of magnitude than for lithium-manganese-borate glass without vanadium 
doping. Microstructure of nanocrystalline samples observed by SEM revealed presence of bigger and smaller grains, including ones below $100 \mathrm{~nm}$, most probably related to the growth of h-LiMnBO 3 phase.

Acknowledgements The authors are grateful to Mr. Adam Presz, Institute of High Pressure Physics, Polish Academy of Sciences for his help in SEM imaging.

Open Access This article is distributed under the terms of the Creative Commons Attribution 4.0 International License (http:// creativecommons.org/licenses/by/4.0/), which permits unrestricted use, distribution, and reproduction in any medium, provided you give appropriate credit to the original author(s) and the source, provide a link to the Creative Commons license, and indicate if changes were made.

\section{References}

1. Pietrzak TK, Wasiucionek M, Michalski PP, Kaleta A, Garbarczyk JE (2016) Highly conductive cathode materials for Li-ion batteries prepared by thermal nanocrystallization of selected oxide glasses. Mater Sci Eng B 213:140-147

2. Pietrzak TK, Garbarczyk JE, Wasiucionek M, Nowiński JL (2016) Nanocrystallization in vanadate-phospate and lithium-ironvanadate-phosphate glasses. Phys Chem Glasses: Eur J Glass Sci Technol, Part B 57:113-124

3. Pietrzak TK, Garbarczyk JE, Gorzkowska I, Wasiucionek M, Nowiński JL, Gierlotka S, Joźwiak P (2009) Electrical properties vs. microstructure of nanocrystallized $\mathrm{V}_{2} \mathrm{O}_{5}-\mathrm{P}_{2} \mathrm{O}_{5}$ glasses. $\mathrm{J}$ Power Sources 194:73-80

4. Garbarczyk JE, Pietrzak TK, Wasiucionek M, Kaleta A, Dorau A, Nowiński JL (2015) High electronic conductivity in nanostructured materials based on lithium-iron-vanadate-phosphate glasses. Solid State Ionics 272:53-59

5. Pietrzak TK, Wasiucionek M, Gorzkowska I, Nowiński JL, Garbarczyk JE (2013) Novel vanadium-doped olivine-like nanomaterials with high electronic conductivity. Solid State Ionics 251:40-46

6. Michalski PP, Pietrzak TK, Nowiński JL, Wasiucionek M, Garbarczyk JE (2017) Novel nanocrystalline mixed conductors based on $\mathrm{LiFeBO}_{3}$ glass. Solid State Ionics 302:40-44

7. Hautier G, Jain A, Chen H, Moore C, Ong SP, Ceder G (2011) Novel mixed polyanions lithium-ion battery cathode materials predicted by high-throughput ab initio computations. J Mater Chem 21:17147-17153

8. Kim JC, Moore CJ, Kang B, Hautier G, Jain A, Ceder G (2011) Synthesis and electrochemical properties of monoclinic $\mathrm{LiMnBO}_{3}$ as a $\mathrm{Li}$ intercalation material. J Electrochem Soc 158(3):A309A315

9. Le Roux B, Bourbon C, Lebedev OI, Colin J-F, Pralong V (2015) Synthesis and characterization of the $\mathrm{LiMnBO}_{3}-\mathrm{LiCoBO}_{3}$ solid solution and its use as a lithium-ion cathode material. Inorg Chem 54:5273-5279
10. Legagneur V, An Y, Mosbah A, Portal R, Le Gal La Salle A, Verbaere A, Guyomard D, Piffard Y (2001) $\mathrm{LiMBO}_{3}(\mathrm{M}=\mathrm{Mn}, \mathrm{Fe}$, Co): synthesis, crystal structure and lithium deinsertion / insertion properties. Solid State Ionics 139:37-46

11. Ma R, Shao L, Wu K, Lao M, Shui M, Chen C, Wang D, Long N, Ren Y, Shu J (2013) Electrochemical behaviors of hexagonal $\mathrm{LiMnBO}_{3}$ as lithium storage host material for lithiumion batteries. Ceram Int 39:9309-9317

12. Kim JC, Li X, Moore CJ, Bo S-H, Khalifah PG, Grey CP, Ceder G (2014) Analysis of charged state stability for monoclinic $\mathrm{LiMnBO}_{3}$ cathode. Chem Mater 26:4200-4206

13. Michalski PP, Gołębiewska A, Trébosc J, Lafon O, Pietrzak TK, Ryl J, Nowiński JL, Wasiucionek M, Garbarczyk JE (2019) Properties of $\mathrm{LiMnBO}_{3}$ glasses and nanostructured glassceramics. Solid State Ionics 334:88-94

14. Hong J, Wang CS, Chen X, Upreti S, Whittingham MS (2009) Vanadium Modified $\mathrm{LiFePO}_{4}$ Cathode for Li-Ion Batteries. Electrochem Solid-State Lett 12(2):A33-A38

15. Omenya F, Chernova NA, Upreti S, Zavalij PY, Nam K-W, Yang X-Q, Whittingham MS (2011) Can vanadium be substituted into $\mathrm{LiFePO}_{4}$ ? Chem Mater 23:4733-4740

16. Hirose K, Honma T, Benino Y, Komatsu T (2007) Glass-ceramics with $\mathrm{LiFePO}_{4}$ crystals and crystal line patterning in glass by YAG laser irradiation. Solid State Ionics 178:801-807

17. Siuzdak K, Szkoda M, Lisowska-Oleksiak A, Karczewski J, Ryl J (2016) Highly stable organic-inorganic junction composed of hydrogenated titania nanotubes infiltrated by a conducting polymer. RSC Adv 6:33101-33110

18. Wysocka J, Krakowiak S, Ryl J (2017) Evaluation of citric acid corrosion inhibition efficiency and passivation kinetics for aluminium alloys in alkaline media by means of dynamic impedance monitoring. Electrochimica Acta 258:1463-1475

19. Pietrzak TK (2019) Multi-device software for impedance spectroscopy measurements with stabilization in low and high temperature ranges working under Linux environment. Ionics 25:24452452

20. Michalski PP, Pietrzak TK, Nowiński JL, Wasiucionek M, Garbarczyk JE (2016) Dependence of a glass transition temperature on a heating rate in DTA experiments for glasses containing transition metal oxides. J Non-Cryst Solids 443:155-161

21. Kissinger HE (1957) Reaction kinetics in differential thermal analysis. Anal Chem 29(11):1702-1706

22. Lasocka M (1976) The effect of scanning rate on glass transition temperature of splat-cooled $\mathrm{Te}_{85} \mathrm{Ge}_{15}$. Mater Sci Eng 23:173-177

23. Austin IG, Mott NF (2014) Polarons in crystalline and noncrystalline materials 18:41-102

24. Pietrzak TK, Pawliszak Ł, Michalski PP, Wasiucionek M, Garbarczyk JE (2014) Highly conductive $90 \mathrm{~V}_{2} \mathrm{O}_{5} \cdot 10 \mathrm{P}_{2} \mathrm{O}_{5}$ nanocrystalline cathode materials for lithium-ion batteries. Procedia Engineering 98:28-35

25. Chen W, Zhang H, Zhang XG, Wu L, Liu J, Liu S, Zhong $S$ (2018) Synthesis and electrochemical performance of carboncoated $\mathrm{LiMnBO}_{3}$ as cathode materials for lithium-ion batteries. Ionics 24:73-81

Publisher's note Springer Nature remains neutral with regard to jurisdictional claims in published maps and institutional affiliations. 